\title{
Determinants of Retention of Psychological Contract of Information Technology Professionals in Sri Lanka
}

\author{
S. A. I. Silva ${ }^{1}$, T. D. Weerasinghe ${ }^{2}$ \\ ${ }^{1}$ Department of Human Resource Management, University of Kelaniya, Sri Lanka \\ ${ }^{2}$ Lecturer, Department of Human Resource Management, University of Kelaniya, Sri Lanka
}

\begin{abstract}
Job hoping of employees has become a tremendous issue in IT firms across the world. Literature reveals that the average period of IT professional remains in a company is around two years. This research paper argues that this issue arises because of current IT firms have failed to retain the psychological contract of IT professionals which was formed at the recruitment and the socialization stages. Building a positive psychological contract in the recruitment stage is not enough to sustain in the current business environment. It is vital to retain the psychological contract as well. This study examines the determinants of psychological contract retention in the domain of IT professionals in Sri Lanka. This cross sectional field study was carried out among a sample of 80 IT professionals. Convenience sampling was applied to select the sample. A self-administered, standard questionnaire was used to gather data. Eighty questionnaire responses from the IT professionals were analyzed using SPSS. Exploratory Factor Analysis (EFA) was performed to find out the determinants of psychological contract retention. KMO statistics was used to determine the sampling adequacy. Factor loading values and extraction sums of squared loadings (cumulative) values were used to draw the conclusion. The results of this exploratory study revealed that work atmosphere is the most prominent factor that contributes to retain the psychological contract among them. Moreover, stimulating job, task description, autonomy, salary satisfaction are the significant determinants of psychological contract retention of IT professionals in Sri Lanka. Finding of this research revealed that job security, intra organizational mobility, work life balance and career development become insignificant to retain the psychological contract of IT professionals in the Sri Lankan Context. Furthermore, it is recommended to give a serious attention to create and maintain a proper work atmosphere through possible policies, procedures and systems in IT firms.
\end{abstract}

Keywords - Psychological Contract, IT Professionals, Retention of Psychological Contact

\section{INTRODUCTION}

In today's dynamic business environment, one of the current issues that Information Technology (IT) Industry faces is Job Hoping of Information Technology Professionals. IT people can be illustrated as highly skilled professionals and also called as knowledge workers. The current trend of these people is hop from one job to another in a very short time period because of the thinking of building multicarrier. The implied meaning of this may be that the organizations have failed to retain the psychological contract.

Onici (2009) cited evidence from Rousseau (1995) and stated that psychological contract forms at the Recruitment \& Selection (R \& S) process. Some researches state the importance of forming the psychological contract at the early beginning of the hiring process (Onici, 2009). But the researcher's argument is that building positive psychological contract at the recruitment stage is not enough. The organizations should strive to retain the psychological contract which was formed at the recruitment stage. If organizations fail to do so, then employees will hop to another.

Herath (2013) has stated that "Discussions with IT industry personnel revealed that the average period IT professional would remain in a company is around two years". So, there are lots of researches that have focused on identifying the reasons to leave the organization in very short time but researches related to retention of psychological contract are very limited. However, although some are hoping one job to another, there are some IT employees who have worked long time in the same job. If those people haven't moved in two or twoand-a-half years, there should be a better good reason for staying at that job. The researcher's argument is that, if these people have bound psychologically to their job, they will not hop one job to another in very shortly. Therefore, the researcher's aim is to identify the reason to stay within the same job, in psychological contract aspect by analyzing the determinants of retention of psychological contract of IT professionals.

Shen (2010) cited evidence from Rousseau and Wade-Benzoni (1994) and stated that "Psychological contracts refer to beliefs that individuals hold regarding promises made, accepted, and relied upon between themselves and another". Because they are subjective, psychological contracts both fill the perceptual gaps in the employment relationship and shape day-to-day employee behaviors in ways that cannot necessarily be discerned from a written contract (Donnell and Shields, 2008). Employees develop their psychological contracts

DOI: $10.9790 / 0837-2109030412 \quad$ www.iosrjournals.org $\quad 4 \mid$ Page


based on their perceptions of the policies and practices, culture and procedures of the organization and the promises made by its representatives (Turnley and Feldman, 1999). An employee's psychological contract starts to develop in the recruitment process and modifies when the individual has more experience in the organization. When employees perceive that the organization has fulfilled effectively its obligations and kept its promises they become more satisfied with their jobs and become more committed to their in-roles and extra roles. Therefore, understanding and meeting psychological contract expectations is the key to success of any organization. The researcher argues that, if the organization can retain the psychological contract of their employees to the organization for long term, then they will not strive to shift another organization within very short time. Therefore, it is vital to know that what factors that organization needs to develop in order to retain the psychological contract of their IT professionals rather than focusing on identifying what is the reason for job-hoping.

According to Social Exchange Theory, it is said that in order to get something from someone we should give something. As mentioned in the research article Treuer (2012), social exchange theory is the most commonly used conceptual framework for understanding contract breach and fulfillment. According to this theory, the development of positive employment relationships is dependent on both employees and their employers abiding by rules of exchange (Blau, 1964). These exchanges can be economic (e.g., money, goods) or more social in nature (e.g. respect, encouragement). When individuals receive benefits they feel obliged to reciprocate, and this norm of reciprocity is central to social exchange theory (Gouldner, 1960). For instance, if employees feel that their employer has not reciprocated, then they may perceive that contract breach has occurred and attempt to restore this balance by lowering their organizational trust or commitment (Taylor and Tekleab, 2004).

Same theory can be applied to an organization too. It means, in order to get the employee loyalty towards the organization, the company should give what employees' implied expectations. Then they are psychologically bound to their organization. Another theory is that Organizational support theory. This theory says that if organizations are ready to give all socio emotional rewards, then the employees will build a belief that the organization will care about them and psychological bond will enhanced.

As said in the literature, there are so many factors that make someone to retain psychologically to a job such as pay satisfaction, work life balance, organization culture, social atmosphere, career development opportunities, reducing stress level, management of the company, scant job opportunities in the market, flexi hours, job security etc. But the researcher's aim is to identify the determinants of psychological contract which are specific to IT Industry and suggest strategies to minimize the job hoping of IT professionals in Sri Lanka.

\section{PROBLEM OF THE STUDY}

In Sri Lanka, the burning issue of IT firms facing is job hoping of IT professionals. In Sri Lanka, the average period a professional would remain in a company is around two years (Herath, 2013). Because of this trend, the Sri Lankan IT Companies face several problems. They have to train workers again; they have to spend more money, time etc. Hemdi and Rahim (2011) cited evidence from Walker and Miller (2010) and suggested that the costs of hiring and supervising a new replacement co-worker, rather than dealing with a coworker who is leaving, can amount to $70 \%$ of his annual salary. In addition, a high turnover rate may lead to the erosion of the company's implicit knowledge base which is one of the important key variables for competitive advantage (Coff, 1997) as in (Hemdi and Rahim, 2011). Hence, an organization's human resources are a prime intangible resource to look for competitive advantage because they take time to develop, and are hard for outsiders to understand and difficult to imitate. A highly skilled labor force can harness and exploit service-base competencies in ways that lead to competitive advantage (Lado \& Wilson, 1994) as in (Hemdi and Rahim, 2011). On the other hand, it is very difficult to find another suitable person to those jobs because those jobs are highly skilled based. The other thing is, in present era of Sri Lanka, lack of the professionals who are competent with IT knowledge is a biggest problem to IT companies as well as to recruit persons and work with them long term. So, this research paper argues that the organizations should strive to retain the psychological contract which was formed at the recruitment and socialization stages. In order to do so, they must have sound knowledge on what are the determinants of psychological contract retention. Therefore, it is beneficial to identify what are the factors that determine the retention of psychological contract of IT professionals in Sri Lanka.

Thus, the research problem of the current study was:

What are the determinants of retention of psychological contract of IT professionals in Sri Lanka?

Accordingly, the main purpose of this study was to identify the factors that determine the retention of psychological contract of IT professionals in Sri Lanka.

III. LITERATURE REVIEW

The importance of an employee's psychological contract within the organization is highlighted by the continued attention given it by way of theoretical and empirical research, yet the definition of the psychological 
contract has varied as the concept has evolved and matured (Argyris, 1960; Herriot \& Pemberton, 1997; Rousseau, 1995; Schein, 1980) as in (Newton 2006).

According to Rousseau (1995), "the psychological contract consists of individual beliefs regarding terms of an exchange agreement between individuals and their organization." An employee's psychological contract includes that person's understanding of his or her own as well as the employer's obligations (Dabos \& Rousseau, 2004; Rousseau, 1995). Psychological contracts emerge when employees believe that their employer has promised to provide certain rewards in return for their contributions (Turnley \& Feldman, 2000).

Bal, Cooman, \& Mol (2013) cited evidence from Rousseau (1995) and stated that psychological contracts contain various aspects of the exchange relationship between the employee and the organization. On one hand, psychological contract consists of certain demands through which employees form perceptions of what their employer is obligated towards them (employer obligations), and on the other hand employees have perceptions of their own obligations about what they should contribute towards their organizations.

The process of psychological contract formation remains theoretically underdeveloped and has received limited empirical attention, with only two exceptions (Robinson, Kraatz, \& Rousseau, 1994; Thomas \& Anderson, 1998) as in Vos, Buyens, \& Schalk, 2003). It was found that during the socialization process newcomers came to perceive that their employers owed them more and they owed less to their employers. Further, Vos, Buyens, \& Schalk (2003) cited evidence from (Robinson et al., 1994) and mentioned that newcomers probably change their psychological contract perceptions based on the reality they encounter after their entry. However, psychological contract is a very dynamic term and is changing continuously during an employment relationship. Besides, there is a big discrepancy between pre-employment beliefs and after increases the occurrence of its violation (Rousseau, 1989 as in Onici, 2009).

Many of the socialization research studies suggest that it is mainly during the encounter stage of socialization, for an example, the first months after entry, that newcomers actively test their anticipations against the reality of their new work experiences. During this period, differences between anticipations and experiences become apparent and contribute to a 'reality shock'. Relating this to psychological contract formation means that this is the period during which perceived promises are most likely to change as a consequence of newcomers' interpretations of their experiences. The individual's adjustment to the organization further occurs during the sixth to twelfth month after entry, in example, the acquisition stage of socialization (Louis, 1980; Schein, 1978) as in (Vos, Buyens, \& Schalk, 2003).

However, all the studies only focused on changes in the mean level of newcomers' psychological contract perceptions without investigating the factors associated with these changes over time. So, the implied meaning of this is that the organizations need not only form a positive psychological contract but also need to do something to retain that psychological contract.

The social exchange theory can be taken as the theoretical foundation of psychological contract. Shapiro, Jacqueline, \& Parzefall (2008) cited evidence from Blau (1964) and stated that social exchange theory examines how social exchange relationships develop in engendering "feelings of personal obligations, gratitude and trust". Social exchange involves unspecified obligations where one party needs to trust the other that the benefits received will be reciprocated. The reciprocation of benefits enhances trustworthiness which in turn facilitates the ongoing conferring of benefits and discharging of obligations over the long term.

Further, Shapiro, Jacqueline, \& Parzefall (2008) explained that the work on social exchange theory shares some common elements with psychological contract theory. First, both view exchange relationships as comprising tangible and intangible resources governed by the norm of reciprocity. Second, each party brings to the relationship a set of expectations/obligations that they will provide in return for what they receive. However, the other party to the exchange (the organization) receives more explicit consideration by psychological contract researchers while the norm of reciprocity was more prominent and theoretically refined by social exchange theorists.

In results of a study of Perceptions of the mutual obligations between employees and employers: a comparative study of new generation IT professionals in China and the United States, King \& Bu (2005) has stated that new IT recruits from China and the US hold many similar beliefs on employer-employee obligations, such as employers' obligations to provide high pay, job autonomy, long-term job security, financial reward for obtaining IT certificates, exciting projects and opportunities to work on leading-edge technology, and employees' obligations to work extra hours when needed, to be loyal and to volunteer to do non-required tasks.

Another variation of psychological contract that exists uniquely for IT professionals is related to terms that tend to be perceived as important in IT functions. IT employees may feel that employers are obligated to reward them if they have worked hard and earned IT certifications or to reward them based on project milestone accomplishments. Because of rapid technological advancement, IT employees may also believe that employers are obligated to provide opportunities to work with leading-edge technologies. To reciprocate, employees may believe that they are obliged to keep their skill-set up to date and complete projects on time (King \& $\mathrm{Bu}, 2005$ ) cited evidence from (Chin et al., 2000). 
Chinese IT recruits are likely to have a stronger emphasis on the relational aspects of the employer obligations such as long-term job security, a weaker emphasis on the transactional aspects of the employer obligations and also a weaker emphasis on both the transactional and relational aspects of the employee obligations (King \& Bu, 2005).In the research article Lee \& Lin (2014) has mentioned that the fairness-based salary is partially significantly correlated to psychological contract, indicating employees care about reasonable salary mechanism, motivating human resource strategy, appropriate reward system and available communication channels. According to Heneman and Schwab (1985), salary satisfaction is defined as the degree to which employees are satisfied with their current salary. Robinson \& Rousseau (1994) has mentioned that a person may expect to be paid market wages in exchange for hard work and feel disappointed when not. A good salary policy can attract and retain talents, preventing employees from leaving their companies due to salary dissatisfaction. Therefore, Salary Satisfaction could be another factor that can retain the psychological contract furthermore. According to Bhargava (2009), the studies examining the impact of human resource on psychological contract of employees suggest the critical role of HRP in influencing employee expectations. The basic tenet of the papers reviewed is that organization's human resource practices (HRP) can change the psychological contract status and influence work related outcomes. Guzzo and Noonan (1994), whose work can be defined as the foundation for many studies examining the relationship between HRM-PC suggest that HRM policies and practices are the "events" that employees in organization interpret . . "much of the information employees rely on to assess the extent to which their psychological contracts are fulfilled comes from HR practices of the employer. How employees interpret and make sense of HR practices affect their psychological contract with their employer, and, ultimately, their commitment to that employer (Guzzo and Noonan, 1994 as cited in Bhargava, 2009).

Scholarios et al (2008) cited evidence from Herriot, Manning \& Kidd (1997) and stated that rewarding careers and career development opportunities are thought to be a central component of employees' psychological contracts. On the other hand, software workers, especially, are likely to be motivated by opportunities for development and status (Kunda 1992; Cappelli 2000; Holm et al., 2002) as in (Scholarios et al., 2008).

Shen (2010) cited evidence from Gillespie et al (2001), Bathmaker (1999), Hrabok (2003) and stated that compared to other professions in commercial sectors, academics have been envied for their tenure, light work load, flexibility, "perks" such as overseas trips for study/conference purposes, and the freedom to pursue their own research interests. University staff did not expect to receive high pay, but cared more about recognition of their contributions. Sometimes, these factors can be the factors of psychological retention as well.

As said in Treuer (2012) in particular, empirical studies have found contract breach to be related to turnover intentions, turnover, and other employee attitudes and behaviors including trust, job satisfaction, organizational commitment and organizational citizenship behavior.

If the employer breaches the psychological contract of employees, then they may strive to leave their job. So, the factors that may affect to leave the organization are the factors to breach the psychological contract of employees. Therefore the researcher's argument is that, the factors that affects to stay or leave the job or organization will ultimately become the factors that affect to retain psychological contract. Therefore, it would be beneficial to observe the factors affect to stay or leave the organization. Psychological contract measures such as job content, promotion, salary, work-family balance, and performance pay were significantly affected turnover intentions (Hemdi and Rahim, 2011).

As said in Shadman (2013) goal clarity is important for employees as it gives them a specific direction towards which they can channelize their efforts. They expect clear communication of organizational goals to them and also aspire to be a co-participant in the formulation of goals. Further, the needs and goals of employees must be aligned with the goals of the organization. Autonomy in thought and action and control over the pace of work has emerged as one of the factors behind an employee's decision to stay. Most employees attach a high value to autonomy and responsibility; freedom to perform a task as an employee deems fit fosters a sense of loyalty in an employee. Opportunities for employee development, freedom to employees to do their best, a mission which makes an employee feel that his/he contribution to the organization is unique, and employee loyalty - all serve to determine the degree of Employee Empowerment, which has a significant impact on employees' intention to stay. Lack of career development programs, lack of recognition, ineffective leadership and inadequate emphasis on teamwork were stated as potential reasons for leaving the organization. Further, characteristics of the job itself, reputation of the company, career advancement opportunities, and job security and organization culture were frequently cited by employees as reasons for choosing to work with the organization.

As said in Hemdi and Rahim (2011) among the psychological contract variables, job content appeared to be the most significant predictor of hotel managers" turnover intentions, followed by promotion opportunities and salary. Thus, the greater the extent to which individuals find that their jobs include challenging, comprehensive and diverse works, the less likely they are to leave their organizations. 
According the research Razaq, Sabir, \& Hameed (2012) has stated that many other factors such as bad market situation, shifting of different companies to other countries, scant job opportunities, growth of uncertainty are affect to retain employees in the same organization. That is why employees do not want to leave their job even offering double golden shake hand and psychologically bounded to stay in same company.

According to the proposed framework for negotiating an expatriate's psychological contract there are specific factors that enhance the psychological contract of expatriates. Those are balance time, reception by employer, external environment, amicable colleagues, knowledge of culture, domestic happiness, obligations and promises, work environment, and notable salary (Lewis, 1997) as in (Guzzo et al., 1994; Rousseau, 1995). Fig: 01 exhibits the specific determinants of retention of psychological contract identified in research literature by different authors.

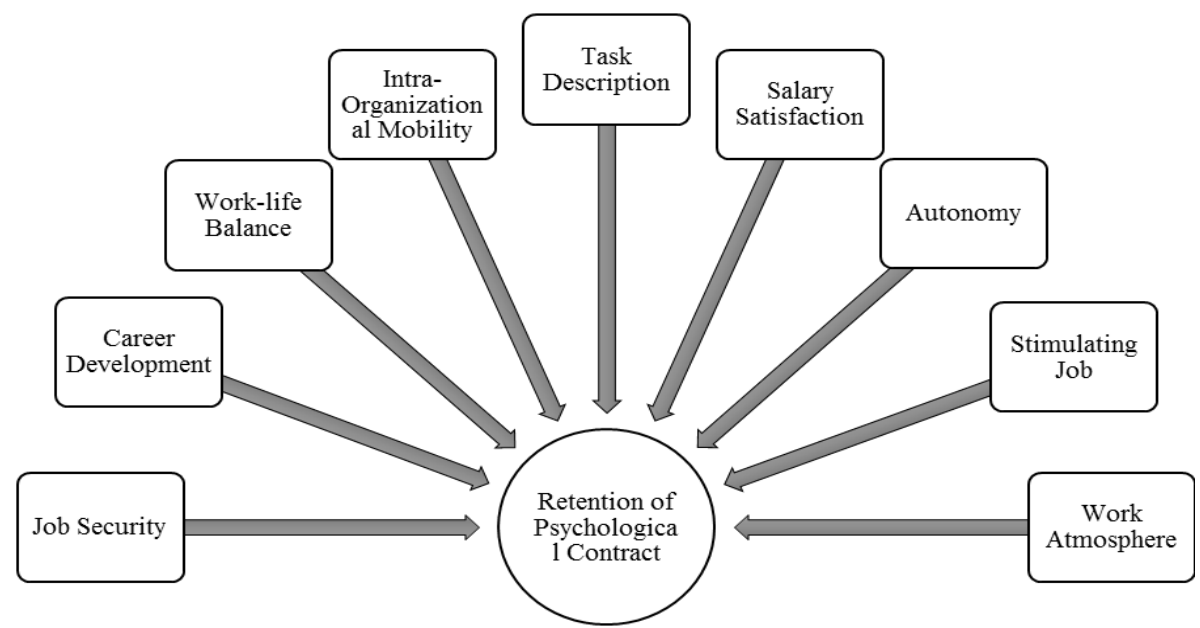

Figure 01: Determinants of retention of psychological contract

\section{MATERIALS AND METHODS}

Researcher used both primary data and secondary data in order to achieve the research objectives. Based on the secondary data which were in journal articles, the researcher short listed some specific determinants of retention of psychological contract in general.

An exploratory research frame was designed to study the determinants of psychological contract. The population includes Information Technology professionals in various companies in Sri Lanka. This is a cross sectional study as data would be collected only in a particular point of time and it did not repeat. Also, researcher interference was minimum in the current study and at the same time this is a field study. Unit of analysis was at the individual level; an individual employees who are working in Sri Lankan IT industry.

In order to achieve the research objectives, the researcher decided to distribute 80 questionnaires to 80 respondents in different sampled companies. Researcher used convenience sample to the study. In the case of primary data collection, a structured questionnaire was distributed among sampled respondents. The questionnaire consisted of two parts. The first section captures demographic information such as age, gender, education, Job position etc. The second section consisted of forty eight items to identify the determinants of retention of psychological contract of IT professionals in Sri Lanka.

Ten brink's (2004) validated psychological contract questionnaire which offers a detailed breakdown of different dimensions of psychological contract was used to measure the eight determinants. Items were posed as statements and read "I find it important that my employer offers me [. . .] (i.e. challenging work)." Respondents were asked to rate their level of agreement for the items on a Five-point Likert scale, ranging from strongly disagree (1) to strongly agree (5).

To measure the reliability (internal consistency) of the questionnaire Cronbach's Alpha technique was functioned. The content validity of the questionnaire was assured by preparing it based on the validated literature. The researcher has taken the items which are having more than 0.5 of Cronbach's Alpha value as reliable. Moreover, an exploratory factor analysis was done to recognize the significant determinants of psychological contract retention of IT professionals. Kaiser-Meyer- Olkin Measure of Sampling Adequacy for the study was 0.833 , which would be labeled as meritorious. Sig value was less than 0.05 . Factors loaded on a particular component with the factor loading value which is greater than 0.7 are taken as significant factors of psychological contract retention. Therefore, it is concluded that five out of nine determinants could explain the total variance of $65.718 \%$ of the psychological contract retention.

DOI: $10.9790 / 0837-2109030412 \quad$ www.iosrjournals.org $\quad 8 \mid$ Page




\section{FINDINGS AND DISCUSSION}

As explain in the table 01, findings revealed that five out of nine determinants of psychological contract retention are significant factors to retain psychological contract of IT professionals. These five factors could explain the total variance of $65.718 \%$ of psychological contract retention of IT professionals in the selected domain. Table 02 depicts the total variance explained by above stated five determinants.

Table 01: Component Matrix (Factor Analysis)

\begin{tabular}{|l|r|}
\hline & \multicolumn{2}{|c|}{ Component } \\
\cline { 2 - 3 } & 1 \\
\hline Stimulating & .859 \\
Job & .874 \\
Work & .789 \\
Atmosphere & .707 \\
Autonomy & \\
Salary & .813 \\
Satisfaction & \\
Task & \\
Description & \\
\hline
\end{tabular}

Notes: (i) Extraction Method: Principal component Analysis; (2) One component extracted

Table 02: Total Variance Explained by Retained Five Factors

\begin{tabular}{|c|r|r|r|r|r|r|}
\hline \multirow{2}{*}{ Component } & \multicolumn{3}{|c|}{ Initial Eigen values } & \multicolumn{3}{|c|}{$\begin{array}{c}\text { Extraction Sums of Squared } \\
\text { Loadings }\end{array}$} \\
\cline { 2 - 6 } & \multicolumn{1}{|c|}{ Total } & $\begin{array}{c}\text { \% of } \\
\text { Variance }\end{array}$ & $\begin{array}{c}\text { Cumulative } \\
\%\end{array}$ & Total & $\begin{array}{c}\text { \% of } \\
\text { Variance }\end{array}$ & $\begin{array}{c}\text { Cumulative } \\
\%\end{array}$ \\
\hline 1 & 3.286 & 65.718 & 65.718 & 3.286 & 65.718 & 65.718 \\
2 & .659 & 13.179 & 78.897 & & & \\
3 & .439 & 8.773 & 87.670 & & & \\
4 & .406 & 8.123 & 95.793 & & & \\
5 & .210 & 4.207 & 100.000 & & & \\
\hline
\end{tabular}

Notes: (i) Extraction Method - Principal Component Analysis.

Therefore, Stimulating job, work atmosphere, autonomy, salary satisfaction, task description are the determinants of retention of psychological contract of them. Job security, Intra organizational mobility, work life balance and career development has been insignificant to retain psychological contract of IT professionals. That means those are the factors that that IT Professionals do not consider when retaining psychological contract to their job. Work atmosphere has the highest factor loading value and it is concluded that work atmosphere is the most prominent factor of psychological contract retention of IT professionals in Sri Lanka. Newton (2006) cited evidence from Cougar et al., (1979) and stated that IT personnel have lower social needs than non-IT personnel. But research findings revealed that current IT people have higher social needs. This means that today's IT professionals retain psychologically if they have nice working atmosphere and pleasant colleagues. However, Spence Laschinger et al (2009) cited evidence from George (2015) and stated that an environment conducive to employee retention is one where the working experience is a pleasant one, the resources are adequate and there is some degree of flexibility. So the findings can be backed by the literature as well.

Secondly, the most significant factor is stimulating job. In the literature review chapter, researcher argued that the factors that affects to stay or leave the job or organization ultimately can become the factors that affect to retain psychological contract. As mentioned in Shadman (2013), an employee quitting an organization is psychologically painful both for the organization as well as for other employees. Factors that influence retention include financial rewards and employee benefits, job enrichment, training and development opportunities, work environment. Therefore, the research findings regarding stimulating job also has the capacity to be supported by the literature. Third most significant factor is Task Description. That means IT firms can retain the psychological contract of their IT professionals if they can offer their employees, a clear description of their tasks, a clear description about what (not) to do in their job and a clear description about what they should deliver in their job. Findings revealed that the IT professionals in Sri Lanka can retain 
psychologically if they have autonomy in their works. That means they find freedom to give a personal touch to their work, they expect opportunity to engage in decisions about execution of their tasks, opportunity to give their opinion about work affairs, opportunity to organize tasks according to their own best judgment and opportunity to take decisions about their work independently.

(Newton, 2006) cited evidence Cheney, (1984) \& Cougar et al., (1979) and mentioned that IT personnel have higher autonomy needs. According to the research findings of King and $\mathrm{Bu}$ (2005), job autonomy was one of expectations of New IT recruits in china. Moreover, Autonomy has also been found to influence turnover decisions amongst IT professionals (Ghapanchi and Aurum, 2011) as in (George, 2015). Therefore, the research findings regarding autonomy can be backed by the literature as well.

Nowadays IT professional retain psychologically if they have salary satisfaction too. But they consider the salary satisfaction after considering the above 4 factors. This research finding will supported by the findings of King and $\mathrm{Bu}$ (2005). According to that article IT people in china expects high pay from their employer. Lee \& Lin ( 2014) also has mentioned that the fairness-based salary is partially significantly correlated to psychological contract, indicating employees car about reasonable salary mechanism, motivating human resource strategy, appropriate reward system and available communication channels.

On the other hand, they seek autonomy and salary satisfaction. Findings revealed that current IT professionals in Sri Lankan context does not consider about the job security. Literature states that the "old" psychological contract of job security in return for loyalty and hard work is now a thing of the past, and that a new trend of multiple career changes and fewer promotional opportunities is emerging (Coles, 1995; Crace, 1995; Herriot and Pemberton, 1995; Hiltrop, 1995; Houlder, 1995; Spillius, 1996; Trapp, 1995) as in (Lewis, 1997). Moreover, there are signs of a new psychological contract emerging in which companies promise to give employees support as they acquire new skills. Employability, rather than stability, is the centre piece of this contract (Houlder, 1995) as in (Lewis, 1997). So, the research findings also revealed that job security is insignificant to retain someone psychologically in present days.

Newton (2006) cited evidence from (Cougar et al., 1979) and stated that IT personnel have higher growth needs and lower social needs than non-IT personnel. Also Scholarios et al (2008) cited evidence from Herriot, Manning and Kidd (1997) and stated that rewarding careers and career development opportunities are thought to be a central component of employees' psychological contracts. But according to the findings of this research, career development has become insignificant and IT professional had not considerable expectations regarding their career development.

Furthermore, work life balance is insignificant to retain Psychological contract of IT professionals. As said in Shadman (2013), work life balance is a factor that makes someone retain in a company. Other literature also says that work life balance is important to make psychological contract. George (2015) cited evidence from Ellenbecker (2003) and stated that work-life balance has become an increasingly important factor for many professional workers. Differences observed across generations suggest that the current generation of professional workers demand flexible work schedules which allow for success in their personal as well as their professional life .However, the research findings explores that the work life balance has become insignificant. Sometimes it can be due to the sample composition of the study. $65 \%$ of the sample was unmarried IT professionals. So, this can be the reason for work life balance became insignificant. Usually unmarried people are less concern about the work life balance than married people. It is conclude that work atmosphere, stimulating job, autonomy, task description and salary satisfaction are the significant determinants of psychological contract retention.

\section{CONCLUSION AND RECOMMENDATIONS}

This research was executed with the aim of identifying the determinants of retention of psychological contract of IT professionals in the domain of Sri Lanka. An Exploratory Factor Analysis (EFA) was performed to find out the determinants of psychological contract retention. KMO statistics was used to determine the sampling adequacy. Factor loading values and extraction sums of squared loadings (cumulative) values were used to draw the conclusion. It is found that work atmosphere, stimulating job, autonomy, task description and salary satisfaction are the significant determinants of psychological contract retention and these factors could explain total variance of $65.718 \%$ of the psychological contract retention.

Hemdi \& Rahim (2011) cited evidence from Rousseau (1995) and mentioned that it is only the individuals who develop psychological contracts and not organizations. Organizations provide individuals with a context in which psychological contracts can evolve and develop. As such, the organization can influence the psychological contract of employees directly through its agents and indirectly through administrative contract 
makers. The findings of this research study provide some important suggestions for managers in IT firms to concentrate on the key predictors of the psychological contract retention of IT professionals.

Organizational policies and practices influence employee's psychological contracts as "contract making" (Rousseau, 1995) as in (Aggarwal \& Bhargava, 2009). In the contract making process, when employees believe that their employers have promised to provide them with some inducements, that belief becomes a part of employees PC (Rousseau, 2001) as in (Aggarwal \& Bhargava, 2009) . Thus employers should be aware of the impact of their human resource policies on employee's expectations. So, the management should draw their special attention on these key 5 determinants when creating and implementing new policies, procedures, and systems, because these are the significant factors that contribute to retain psychological contact of these people. Despite the constructive recommendations given in the study, limitations are inevitable. One is sample size might be insignificant. As said in the chapter 3, researcher got 80 IT professionals as the sample. On the other hand, there may be cross sectional sampling errors as well. Another thing is that research findings can generalize only for IT professionals in Sri Lankan domain. Research findings may differ if it applies for another type of employees. There are several important ways in which future research could extend the findings of the findings of the present investigation. Future research should focus on expanding the sample size which can represent high volume of the population. On the other hand, these research findings can be generalized into IT professionals in Sri Lanka. So, future researchers are encouraged to study this retention of psychological contract concept to various types of employees. Moreover, future researchers are encouraged to observe impact of generation type on retention of psychological contact. Future researchers also encouraged to test this concept in different domains as well. In addition, it would be especially helpful for future research to examine, both theoretically and empirically, issues related to the organizational context in which psychological contract is retained or broken. While the researcher did not have the data needed to examine such variables organizational characteristics, industry sectors, or economic trends that may have impacted the retention of psychological contract, future researchers should consider the impact of these variables too.

\section{REFERENCES}

[1] Atkinson, C. (2002). Career management and the changing psychological contract. Career Development International, 14 - 23.

[2] Bhargava, U. A. (2009). Reviewing the relationship between human resource practices and psychological contract and their impact on employee attitude and behaviors. Journal of European Industrial Training, 4 31.

[3] Chi, S.-C. S., \& Chen, S.-C. (2007). Perceived psychological contract fulfillment and job attitudes among repatriates. International Journal of Manpower.

[4] George, C. (2015). Retaining professional workers: what makes them stay? Employee Relations.

[5] Hemdi, M. A., \& Rahim, A. (2011). The Effect of Psychological Contract and Affective Commitment on Turnover Intentions of Hotel Managers. International Journal of Business and Social Science.

[6] Ing, Hao, H. C., Chih, C. L., \& Chuang, H. (2006). Constructing factors related to worker retention. International Journal of Manpower, 491 - 508.

[7] King, R. C., \& Bu, N. (2005). Perceptions of the mutual obligations between employees and employers: a comparative study of new generation IT professionals in China and the United States. The International Journal of Human Resource Management, 46-64.

[8] Lee, H.-W., \& Lin, M.-C. (2014). A study of salary satisfaction and job enthusiasm -mediating effects of psychological contract. Applied Financial Economics, 1577-1583.

[9] Lewis, K. G. (1997). Breakdown - a psychological contract for expatriates. European Business Review, 279 - 293.

[10] Lub, X., Bijvank, M. N., Bal, P. M., Blomme, R., \& Schalk, R. (2012). Different or alike. International Journal of Contemporary Hospitality Management, 553 - 573.

[11] Matthijs Bal, P., De Cooman, R., \& Mol, S. T. (2013). Dynamics of psychological contracts with work engagement and turnover intention: The influence of organizational tenure. European Journal of Work and Organizational Psychology, 22:1, 107-122.

[12] Newton, K. S. (2006). The information technology professional's psychological contract viewed through their employment arrangement and the relationship to organizational behaviors. Graduate Theses and Dissertations.

[13] Onici, T. (2009). An investigation into psychological contract formation from recruitment material in the context of public administration system.

[14] Razaq, A., Sabir, S. M., \& Hameed, R. M. (2012). Retention of Adept Employees: Preliminary Study on PTC- Pakistan. IOSR Journal of Business and Management. 
[15] Robinson, S., \& Rousseau, D. (1994). Violating the psychological contract: not the exception but the norm. JOURNAL OF ORGANIZATIONAL BEHAVIOR.

[16] Scholarios, D., Heijden, B., Schoot, E. V., Bozionelos, N., Epitropaki, O., Jedrzejowicz, P., et al. (2008). Employability and the psychological contract in European ICT sector SMEs. The International Journal of Human Resource Management, 1035-1055.

[17] Shadman, P. G. (2013). Who stays with you?Factors predicting employees' intention to stay. International Journal of Organizational Analysis, 288 - 312.

[18] Shapiro, C., Jacqueline, \& Parzefall. (2008). Psychological contracts. London: SAGE Publications.

[19] Shen, J. (2010). University academics' psychological contracts and their fulfilment. Journal of Management Development, 575-591.

[20] Treuer, S. M. (2012). An examination of psychological contracts, careerism and ITL. Career Development International, 475 - 494.

[21] Vos, A. D., Buyens, D., \& Schalk, R. (2003). Psychological contract development during organizational socialization: adaptation to reality and the role of reciprocity. Journal of Organizational Behavior. 